J.Lake Sci.(湖泊科学), 2016, 28(1): 225-236

DOI 10. 18307/2016. 0126

(C) 2016 by Journal of Lake Sciences

\title{
定常风对鄱阳湖水动力的影响”
}

\author{
姚 静 $^{1}$, 张 奇 ${ }^{1,2 * *}$, 李云良 ${ }^{1}$, 李梦凡 ${ }^{1,3}$ \\ (1: 中国科学院南京地理与湖泊研究所, 中国科学院流域地理学重点实验室, 南京 210008) \\ (2: 江西师范大学, 鄱阳湖湿地与流域研究教育部重点实验室,南昌 330022) \\ (3: 中国科学院大学, 北京 100049)
}

\begin{abstract}
摘 要: 鄱阳湖属大风区, 风场作为仅次于流域 “五河”倾泻和长江顶托作用的另一重要驱动力,或在某些时刻影响局部 区域的水流结构, 进而影响局部水体中泥沙、污染物、营养盐等物质的输移和扩散. 基于鄱阳湖二维水动力数学模型, 模拟 定常风场条件下的鄱阳湖流场分布及环流形式, 并与无风条件下的水流时空结构进行对比. 结果表明: $3.03 \mathrm{~m} / \mathrm{s}$ 的 NE 向 和 SSW 向定常风对湖泊水位影响微弱; 对流速的影响主要集中在 7 月中旬至 9 月底的 “湖相” 期; 其影响区域主要分布在 湖区中部大湖面偏西岸及东部湖湾, 约占湖泊最大水面积的 $16 \%$; 上述区域出现明显环流, 环流结构具有时空异质性特 点, 环流区流速普遍增至无风时的两倍以上; NE 向和 SSW 向风场产生的环流位置相近, 方向相反. 相比于以往鄱阳湖水 动力研究中对风场的忽略, 本次研究揭示了定常风场对鄱阳湖的重点影响区域、影响程度及影响形式, 可为泥沙及污染 物输移模拟中对风场条件的处理及可能带来的误差与误差的空间分布提供重要依据.
\end{abstract}

关键词: 水动力模拟;定常风; 风生环流;鄱阳湖

\section{The influence of uniform winds on hydrodynamics of Lake Poyang}

\author{
YAO Jing ${ }^{1}$, ZHANG Qi ${ }^{1,2 * *}$, LI Yunliang ${ }^{1} \&$ LI Mengfan ${ }^{1,3}$ \\ (1: Key Laboratory of Watershed Geographic Sciences, Nanjing Institute of Geography and Limnology, Chinese Academy of \\ Sciences, Nanjing 210008, P.R.China) \\ (2: Key Laboratory of Poyang Lake Wetland and Watershed Research, Ministry of Education, Jiangxi Normal University, Nan- \\ chang 330022, P.R. China) \\ (3: University of Chinese Academy of Sciences, Beijing 100049, P.R.China)
}

\begin{abstract}
Lake Poyang is a strongly wind-affected region. The wind stress, as the secondary driver after the catchment forcing and effect of the Yangtze River, may influence the flow pattern of local lake body at certain times, which affects the transport and diffusion processes of sediment, pollutants and nutrient substances. Based on two-dimensional hydrodynamic model, the flow distributions and circulation patterns were simulated under uniform wind conditions. Comparisons were made between cases of no wind and uniform wind in order to investigate the spatiotemporal patterns of the flow. The results showed that, for NE and SSW steady winds at $3.03 \mathrm{~m} / \mathrm{s}$ speed, the impact of wind on water level was negligible, and the effect on flow was mainly restricted to the west coast and eastern bay between the middle of July and the end of September. In the affected regions( about $16 \%$ of the total lake area), obvious circulations were noted, which showed spatial and temporal variability, and where average flow velocity was approximately twice as much as that for no wind condition. NE and SSW wind-driven circulations occurred in similar locations but corresponding flow directions were opposite. In comparison to previous hydrodynamic simulations of Lake Poyang that ignored wind effect, this study enhanced the understanding of the location, magnitude and pattern of uniform wind forcing effect on flow. It hints the potential uncertainty in sediment and pollutant transport modelling when dealing with wind conditions.
\end{abstract}

Keywords: Hydrodynamic simulation; uniform wind; wind-driven circulation; Lake Poyang

* 国家重点基础研究发展计划 “973” 项目 (2012CB417003)、江西省重大生态安全问题监控协同创新中心项目 (JXSEW-00) 和国家自然科学基金项目 (41301023,41371062)联合资助.2014-12-05 收稿; 2015-04-18 收修改稿. 姚 静(1980 ), 女, 助理研究员; E-mail: jyao@ niglas.ac.cn.

** 通信作者;E-mail: qzhang@ niglas.ac.cn. 
湖泊水动力过程对湖泊中的物质、能量的输移扩散起着决定性作用. 湖泊水流的数值模拟是泥沙、污染 物、生态等各要素模拟的基础.对大型宽浅且相对封闭的湖泊而言, 风为水流的主要驱动力. 风场的存在, 改 变了水流的流速和运动轨迹, 影响泥沙、污染物、营养物质等输移、扩散及再悬浮, 进而影响水质及水生生态 系统 ${ }^{[1-4]}$.这使得准确模拟并评估风场对水动力场的影响作用显得尤为重要.

在我国, 太湖即为典型的风生流湖泊, 太湖风生流的数值模拟研究, 开展得较早且深人 ${ }^{[5-10]}$.与太湖湖盆 地形相对平坦、水位变幅较小的水情地貌特点相比, 鄱阳湖情况截然不同. 鄱阳湖作为我国最大的通江湖泊, 受赣江、抚河、信江、饶河、修水“五河” 来水及长江来水的双重影响, 属吞吐型、季节性湖泊.鄱阳湖地形变化 极具空间异质性特点, 湖盆自东向西、由南向北倾斜, 南北高程落差达 $10 \mathrm{~m}$, 南北最大长度为 $173 \mathrm{~km}$, 最宽处 $70 \mathrm{~km}$, 人江通道最窄处约 $2.8 \mathrm{~km}^{[11]}$. “五河” 来水自上游注人后, 在重力作用下, 沿河道及洲滩, 顺地势向下 游推进, 至湖口汇人长江. 受 “五河” 和长江来水的季节性变化影响, 鄱阳湖水位变幅巨大 (可达 $10 \mathrm{~m}$ 以 上) ${ }^{[11]}$, 高水湖相、低水河相, 湖流类型以重力型吞吐流为主, 风生流仅为次要类型 ${ }^{[12]}$.

以往有关鄱阳湖水动力模拟方面的研究, 水流驱动力主要考虑 “五河” 来水倾泻和长江顶托作用, 通过 建立鄱阳湖水动力数学模型, 模拟鄱阳湖的水位、湿地面积等变化评价环境影响, 取得了良好的模拟效 果 ${ }^{[13-17]}$. 这些研究均未考虑风作为次要因素的影响,但并不影响整体水位模拟效果. 但需要强调的是, 鄱阳湖 属大风区, 据文献 ${ }^{[18]}$ 报道, 星子湖区 6 级以上大风年内最多达 $86 \mathrm{~d}$, 年均 $45 \mathrm{~d}$, 棠荫站曾实测到风速 $31 \mathrm{~m} / \mathrm{s}$. 加之鄱阳湖幅员辽阔, 湖泊地形复杂, 河道、岛屿、碟形洼地与滩地并存, 大湖面时期, 在局部地形和风场的 共同作用下, 或可能出现风生流占主导的情形. 目前为止, 鄱阳湖盛行风在哪些时段有着颇为显著的影响作 用? 在空间尺度上其影响范围究竟有多大? 其影响形式和程度是怎样的? 不同湖区对风场有着怎样的响 应程度? 这些问题至今仍缺乏系统认识和深人研究.

鉴于以上几点, 本文在鄱阳湖二维水动力数学模型基础上, 设置定常风场, 模拟定常风场影响下鄱阳湖 水流空间结构及变化过程,分析风场对鄱阳湖的主要影响区域、影响量级及流态响应形式. 本研究结果不仅 有助于阐释空间湖流形态对风场的响应机制, 还可为泥沙及污染物输移模拟中对风场条件的处理及可能带

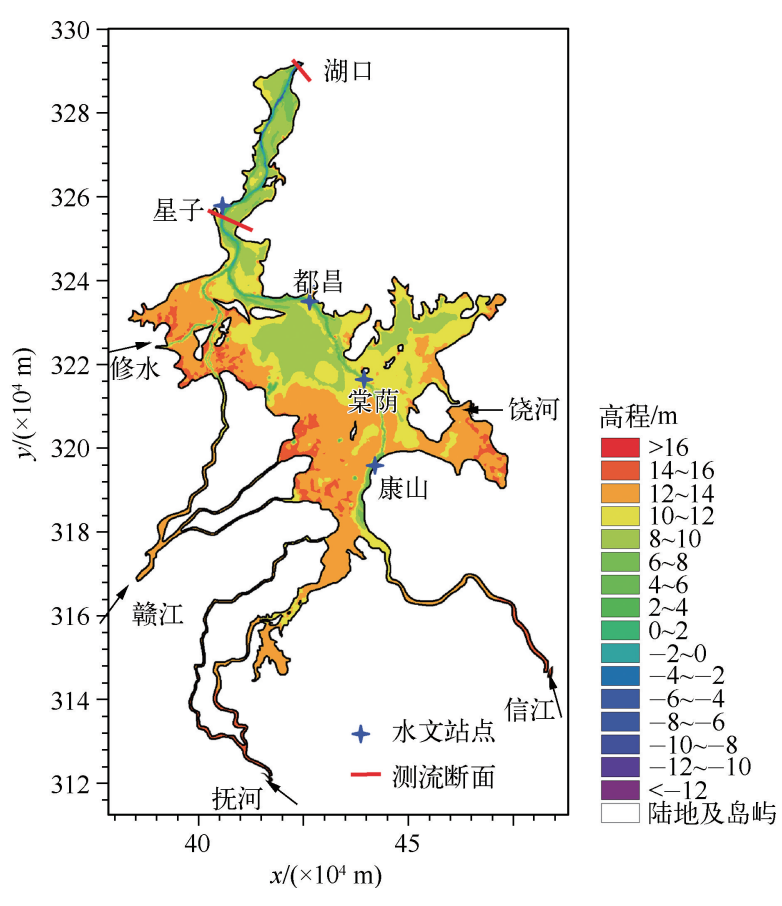

图 1 鄱阳湖地形及水文站点分布

Fig.1 Bathymetry of Lake Poyang and locations of hydrological gauging stations in the lake
来的误差与误差的空间分布提供重要依据, 更重要的是该成果可用于进一步解释鄱阳 湖水环境的空间异质特性及其影响因素.

\section{1 研究方法与方案设计}

\section{1 水动力学模型}

鄱阳湖属宽浅型湖泊,水体垂向混合较 好 ${ }^{[19]}$, 适用于二维水动力数学模型. 针对鄱 阳湖岸线曲折复杂、地形起伏多变、水位变 幅巨大的特点, 选择基于无结构网格的 MIKE 21 模型. 一方面, 无结构网格可以更 好地拟合地形和岸线, 而且通过灵活的加密 技术, 对曲折的湖中河道进行局部加密, 可 达到对地形的准确刻画; 另一方面, 模型中 的干湿判别方法, 通过设置最小干、湿水深, 判断网格是否参与计算, 可准确模拟鄱阳湖 大面积频繁露滩、淹没过程.

基于 MIKE 21 的鄱阳湖二维水动力数 学模型计算范围及岸线边界根据湖泊历史 洪水淹没范围确定 (图 1, 基面为 85 国家高 程). 流域五河的人湖径流过程作为水动力 模型上游开边界条件, 湖泊出口湖口处水位 
过程作为下游开边界条件. 模型采用三角形网格, 为了更好地刻画湖中河道地形变化, 对主河道区域进行局 部网格加密处理, 最小网格为 $70 \mathrm{~m}$, 而远离主河道的洲滩区域网格分辨率相对较粗, 最大网格尺寸为 $1500 \mathrm{~m}$, 共计剖分网格 20450 个.该模型作为鄱阳湖水文水动力联合模拟系统中的水动力模块, 已成功再现 鄱阳湖水动力时空变化过程 ${ }^{[15-16]}$. 模型参数设置和率定过程详见文献 [15-16]. 反映风场的表面风应力计算 公式为:

$$
\overline{\tau_{s}}=\rho_{\mathrm{a}} c_{\mathrm{d}}\left|\overline{u_{\mathrm{w}}}\right| \overline{u_{\mathrm{w}}}
$$

式中, $\rho_{\mathrm{a}}$ 为空气密度, $c_{\mathrm{d}}$ 为风应力拖曳系数, $\overline{u_{\mathrm{w}}}$ 为湖面上空 $10 \mathrm{~m}$ 处风速. 根据 $\mathrm{Wu}^{[20-21]}$ 的经验公式, 拖曳系数 $c_{\mathrm{d}}$ 取为常数 $1.255 \times 10^{-3}$.

\section{2 鄱阳湖水情}

鄱阳湖属过水型湖泊, 湖流以吞吐流为主 ${ }^{[19]}$, 平均换水周期约为 $21 \mathrm{~d}^{[14]}$. 为配合风场资料时间序列, 选取 2010 年作为代表年份进行水动力数值模拟.据 2010 年实测资料统计, “五河” 流量年内平均为 $5075.2 \mathrm{~m}^{3} / \mathrm{s}$, 受 暴雨影响, 6 月 21 日达年内峰值 $44719 \mathrm{~m}^{3} / \mathrm{s}$. 湖泊水位以星子站为代表, 最高水位 $20.28 \mathrm{~m}$, 最低水位 $7.75 \mathrm{~m}$, 水位最大变幅 $12.53 \mathrm{~m}$; 平均水位 $13.84 \mathrm{~m}$, 比该站 1960-2010 年多年平均水位高 $0.49 \mathrm{~m}$. 基于水位一面积及 水位-库容曲线 ${ }^{[22]}$ 可得, 2010 年湖盆区最大水面面积 $3265.5 \mathrm{~km}^{2}$, 对应库容 $275.8 \times 10^{8} \mathrm{~m}^{3}$, 最小水面面积 $550 \mathrm{~km}^{2}$, 对应库容 $13.1 \times 10^{8} \mathrm{~m}^{3}$.

\section{3 模型验证}

该模型已对 2000-2008 年的水位、水面积、流量、流场等水动力指标进行了全面的率定和验证 ${ }^{[15-16]}$, 表 明模型具有关键过程模拟方面的能力和优势, 故此处仅对 2010 年的水动力过程进行进一步验证. 对湖区南 北分布的 4 个主要水文站点(图 1) 的水位过程(图 2) 和湖口站的流量过程(图 3) 进行验证, 验证误差见表 1.结果显示, 水位和流量过程吻合较好, 除湖口流量验证误差稍大外, 其余各水位验证相对误差均在 $\pm 3 \%$ 之 内, 确定性系数均在 0.98 以上, Nash-Sutcliffe 效率系数也均达 0.95 以上. 流速验证方面, 从以往鄱阳湖水动 力模拟研究来看, 缺乏流速资料验证是一直以来共同面临的问题. 如何在缺乏资料的情况下, 有效地验证流 速的真实性和准确性? 自 2013 年底开始,于星子和湖口附近,进行多次 ADCP 断面流速监测 (图 1), 积累了 部分流速断面资料. 本文选取 2014 年 5 月 23 日星子断面和 2013 年 12 月 4 日湖口断面的流速监测资料, 分 别代表洪、枯季(高、低水位) 的流速情况. 由于缺乏 2010 年之后的水文数据,无法模拟 2013 、2014 年的同时
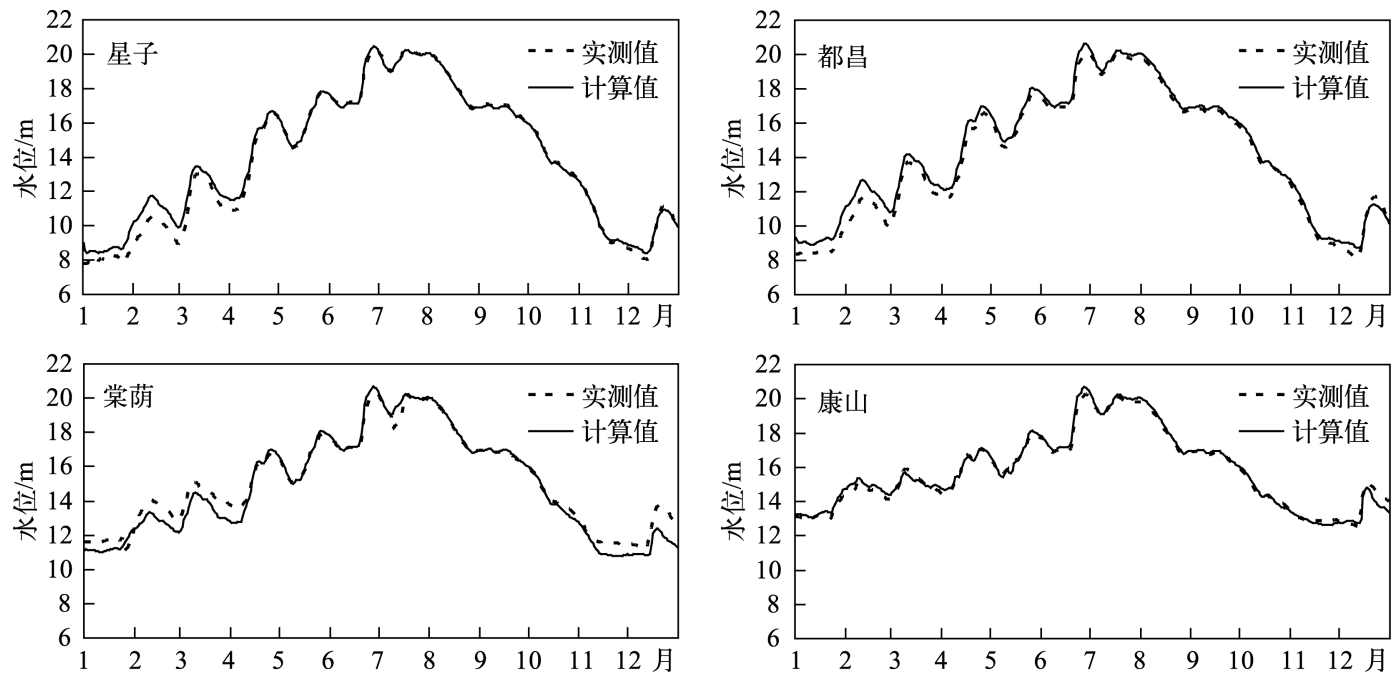

图 22010 年鄱阳湖水位验证

Fig.2 Validation of water levels at four hydrological gauging stations in 2010 


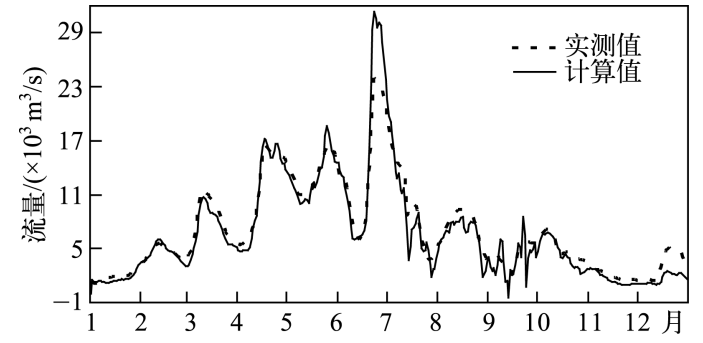

图 32010 年湖口站流量验证

Fig. 3 Validation of discharge at Hukou hydrological gauging station in 2010

表 12010 年模型验证误差

Tab.1 Model validation errors in 2010

\begin{tabular}{lccc}
\hline 站点 & 相对误差 $/ \%$ & 确定性系数 & Nash-Sutcliffe 效率系数 \\
\hline 星子 & 1.8 & 0.994 & 0.987 \\
都昌 & 2.8 & 0.995 & 0.983 \\
棠荫 & -1.5 & 0.983 & 0.958 \\
康山 $^{1)}$ & 0.6 & 0.992 & 0.988 \\
湖口 $^{1)}$ & -4.7 & 0.945 & 0.904 \\
\hline
\end{tabular}

1) 湖口为流量验证, 其余 4 站为水位验证.
刻流速断面并与实测值进行比较. 为使不同年 份的流速具有可比性, 选择本模型水情与 2010 年相近的时期进行流速对比. 2014 年 5 月 23 日测得星子附近断面水位约为 $18 \mathrm{~m}$, 流量为 $11280.1 \mathrm{~m}^{3} / \mathrm{s}$, 根据 2010 年的模拟情况, 选择 5 月 26 日水位 $17.8 \mathrm{~m}$ 、流量 $12200.6 \mathrm{~m}^{3} / \mathrm{s}$ 条件下的 星子断面流速与之比较; 2013 年 12 月 4 日测得 湖口断面水位 $7.4 \mathrm{~m}$ 、流量 $1386.9 \mathrm{~m}^{3} / \mathrm{s}$, 选取 计算的 2010 年 12 月 8 日水位 $8.1 \mathrm{~m}$ 、流量 $1207.1 \mathrm{~m}^{3} / \mathrm{s}$ 条件下的湖口断面流速与之对 比. 断面以河道左岸为起点, 沿垂直河道方 向, 至右岸结束, 枯水时由于水量减少、河宽 收缩, 实际监测距离小于模型中的左右岸边 界距离. 从断面流速对比可知 (图 4), 在相似 水情条件下, 流速断面从量级到分布趋势都 比较接近,但毕竟不同年份水情不可能完全 相同, 流速量值存在一定的偏差, 且由于不同 年份断面局部地形变化,存在小范围内流速 变化不一致的情形 (图 4a).总体而言,这种流 速对比方法在缺乏验证资料的情况下也不失 为一种可行的替代方式. 综上所述, 模型在 2010 年水位、流量和流速方面模拟较好, 能真 实反映水动力变化过程.
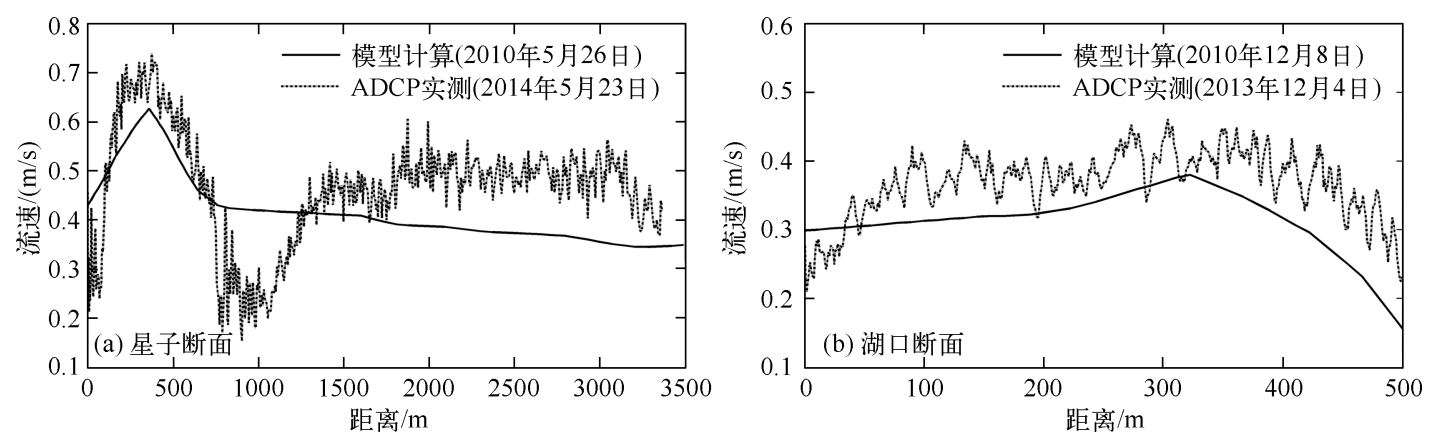

图 42010 年星子断面和湖口断面流速验证

Fig.4 Validation of velocity at Xingzi and Hukou cross sections in 2010

\section{4 风场分析及模拟方案}

风场数据采用位于星子县的鄱阳湖湖泊湿地观测研究站标准气象场实测的 2010 年 $1-12$ 月每日 3 次 $(8: 00 、 14: 00 、 20: 00)$ 的风速、风向资料, 其中 $11 、 12$ 月只有风向资料, 风速资料缺测. 鄱阳湖水面辽阔, 各处 风场并不均匀, 但由于缺乏多站点实测风场资料, 因此假定全湖风场空间均一, 以星子站实测风场为代表进 行计算.鄱阳湖水情复杂, 受“五河” 和长江来水双重影响,不同季节“河相”、“湖相”相互转换.模拟不同水情 叠加变化的风场组合, 难以区分风场影响. 本文侧重关注鄱阳湖盛行风风向对水动力场的影响, 因此从最基 本的定常风模拟人手, 统计出现频次最多的风向及其对应的平均风速, 模拟该风向、风速对不同季节、不同 水情的湖泊水流影响方式及差异, 而不同风速大小的影响差异需要在此基础上做进一步测试研究, 本文中 不予以考虑. 
以往观测及研究结果 ${ }^{[12,18,23]}$ 表明, 除 6-8 月盛行偏南风外, 鄱阳湖全年大多时间为偏北风. 从星子站 2010 年全年及 6-8 月的风玫瑰图 (图 5) 可知,星子站全年的常风向为 NE 向,6-8 月的常风向为 SSW 向, 与以往结论相吻合.

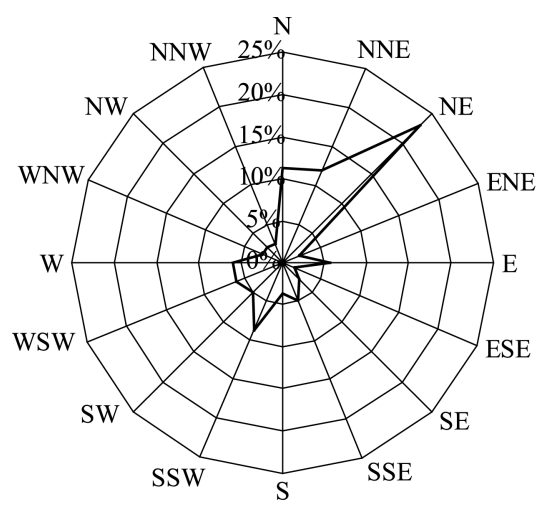

(a) $1-12$ 月

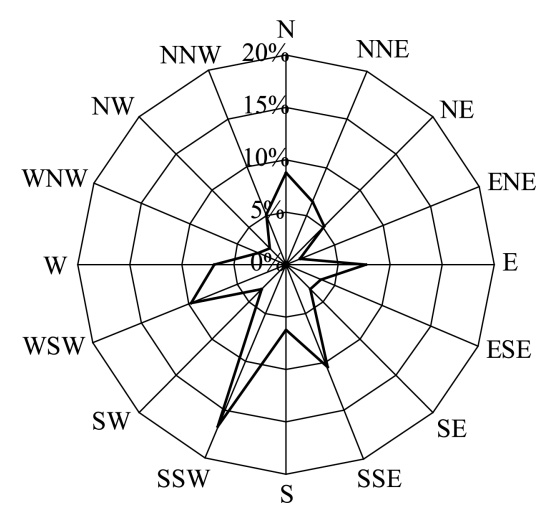

(b) $6-8$ 月

图 5 星子站风玫瑰图

Fig.5 Rose diagram of wind direction at Xingzi station

分别模拟 2010 年整年无风、NE 向定常风、SSW 向定常风 3 种情景的水动力变化过程. 根据实测资料统 计的 $\mathrm{NE}$ 向风对应的平均风速为 $3.03 \mathrm{~m} / \mathrm{s}$, 将该值设为 $\mathrm{NE}$ 向定常风风速, 为方便比较, $\mathrm{SSW}$ 向定常风风速也 取为 $3.03 \mathrm{~m} / \mathrm{s}$.

\section{2 结果与分析}

\section{1 风场对主河道的影响}

为分析风场对鄱阳湖各水动力要素的影响, 首先提取 4 个水文站点有风、无风条件下的水位、流速、流 向过程曲线 (图 6). 由图 6 可知,在 $3.03 \mathrm{~m} / \mathrm{s}$ 的风速条件下,无论是 $\mathrm{NE}$ 向还是 $\mathrm{SSW}$ 向风,各站点水位变化过 程与无风条件下的基本吻合, 即该风场条件对水位的影响很微弱.流速、流向方面, 7 月中旬至 9 月底的 “湖 相” 期, 棠荫、康山站受风的影响相对明显, 主要是因为 “湖相” 期受长江顶托作用, 重力流变缓, 水面开阔, 有 利于风生流的形成,而棠荫、康山站正处于开阔大湖面.

\section{2 风场对流速场的影响}

为进一步分析风场对空间流速场的影响, 针对影响显著时段, 分别计算 NE 向和 SSW 向风场作用下 7 月 20 日至 9 月 30 日期间全场平均流速分布, 并与无风条件下的该时段全场平均流速分布相比. NE 向风场 作用下, 湖区大部分浅滩区域流速减小, 量级小于 $0.5 \mathrm{~cm} / \mathrm{s}$, 相反, 河道流速存在不同程度的增大; SSW 向风 场作用下, 与 $\mathrm{NE}$ 向相反, 大部分浅滩区域流速增大, 增幅也在 $0.5 \mathrm{~cm} / \mathrm{s}$ 以内, 而河道流速存在不同程度的减 小 (图 7). 主要原因为: 浅滩相对河道而言, 水深较浅, 更易受风的影响, NE 向风与主要流向相逆, 对浅滩水 流产生阻碍作用, 而 SSW 向风顺应主流向, 对浅滩水流有一定的推动作用, 主河道因水深较深, 流速较大, 在 重力流作用下并不直接受风的影响,而是在周围浅滩水体流速变化带动下,产生反方向的流速补偿.无论哪 种风向, 在湖区中部湖湾及中部西岸, 均存在明显的流速增大区, 流速普遍增至两倍以上, 最大增幅为 2.0 $2.5 \mathrm{~cm} / \mathrm{s}$. 对照流场图可以发现, 上述区域流速增大主要是由环流引起的, 由于地处开阔的大湖面, 流速相对 缓慢, 而水深变化较大, 极易形成风生环流. 明显环流区面积可达 $600 \mathrm{~km}^{2}$, 约占湖泊最大水面积的 $16 \%$.

\section{3 典型环流区分析}

鉴于上节流速变化的空间分析结果, 结合流场随时间的变化过程, 划分出风生环流比较明显的 3 个局 部区域(图 8), 以便进行局部流场的详细比对. 图中 A 区位于东部湖湾, B 区位于东南部湖湾, C 区位于湖区 中部偏西.重点分析受风场影响最为明显的时段,即 7 月中旬至 9 月底. 

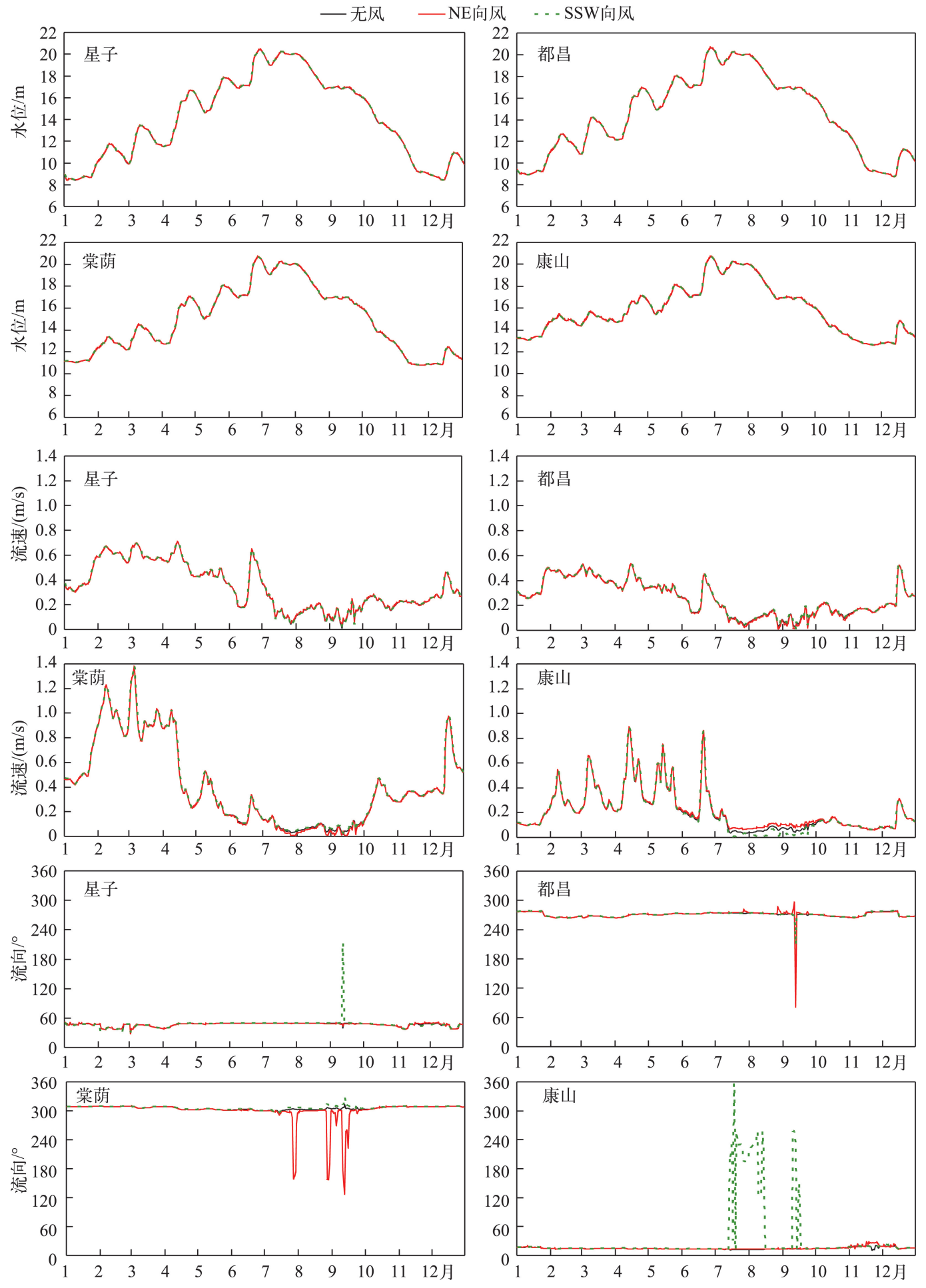

图 6 有风、无风条件湖区水位、流速与流向变化过程曲线

Fig.6 Comparisons of water level, current speed and current direction of four hydrological gauging stations with no wind, NE wind and SSW wind 

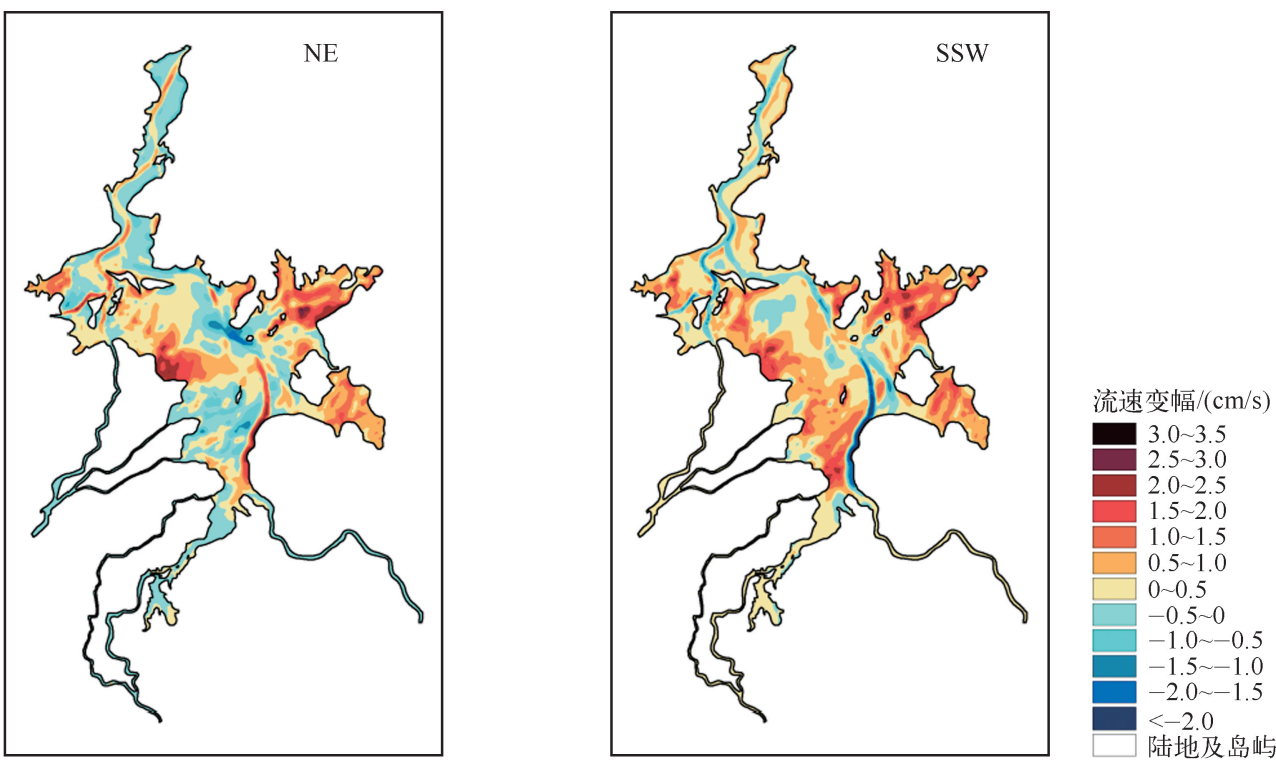

图 7 有风与无风条件相比全场平均流速变幅分布

(7月 20 日-9 月 30 日,正值代表流速增大,负值代表流速减小)

Fig.7 Spatial distribution of average current speed difference between wind conditions and no wind condition (July 20th - September 30th, positive for increasing current speed and negative for decreasing current speed)
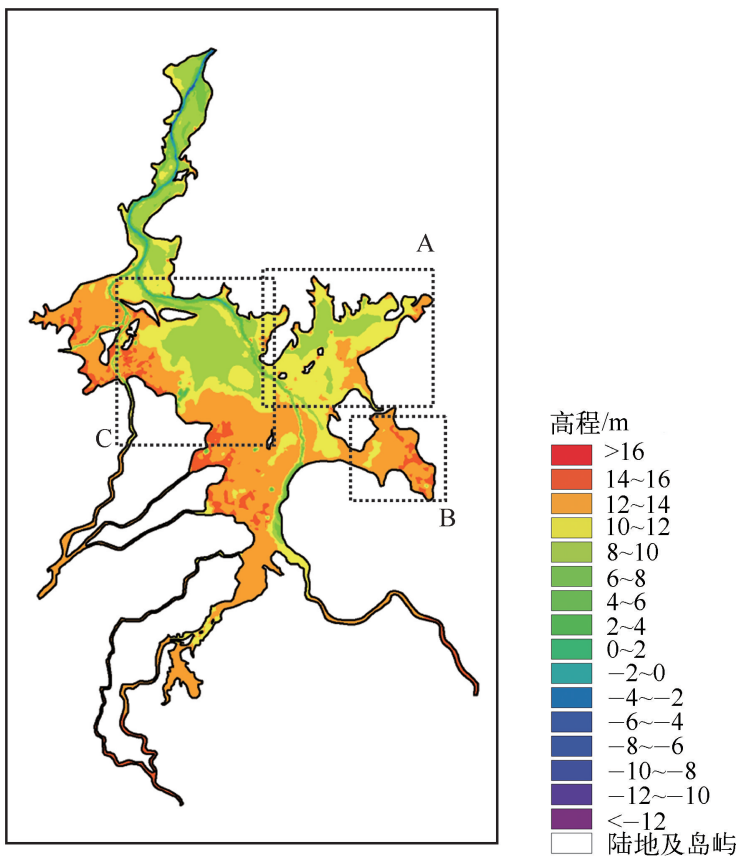

图 8 典型环流区划分

Fig.8 Typical circulation regions

从流场变化来看, 7 月中旬至 9 月底, $\mathrm{A}$ 区、 $\mathrm{B}$ 区在两种风场作用下均存在稳定的环流, 故选择 8 月 8 日 
的流场作为典型流场进行分析.

A 区 (图 9) 地形南高北低, 北部近岸区常年有水, 但流速极小, 近乎停滞. 在 NE 向风场作用下,东南部的 湖滨浅水区水体最易受影响,顺风向自东北流向西南,胁迫东南入湖口处水流也向西南向偏移, 拉动北部深 水湖区水体形成补偿流, 依地形走势呈顺时针方向旋转形成最大直径 $18 \mathrm{~km}$ 的环流涡旋; 西北部小湖湾, 在 主河道和束窄的湖岸共同影响下, 也形成了小尺度顺时针环流. 而在 SSW 风场作用下, 东南部浅水区仍受风 场直接影响, 流向与风向一致, 指向东北, 导致东部整体流态呈 $\mathrm{S}$ 型, 在与 $\mathrm{NE}$ 向风生环流相同位置, 形成了 逆时针环流, 同时在岛屿的东南部, 受微地形和周围流态影响, 也存在逆时针环流浴旋; 西北部湖湾虽未形 成封闭环流,但流向发生了偏逆时针方向的变形. $\mathrm{A}$ 区不同风场引起的主要环流方向符合以往研究规律, 即 浅水区风生流向与风向一致, 深水区则与风向相反 ${ }^{[24-25]}$.
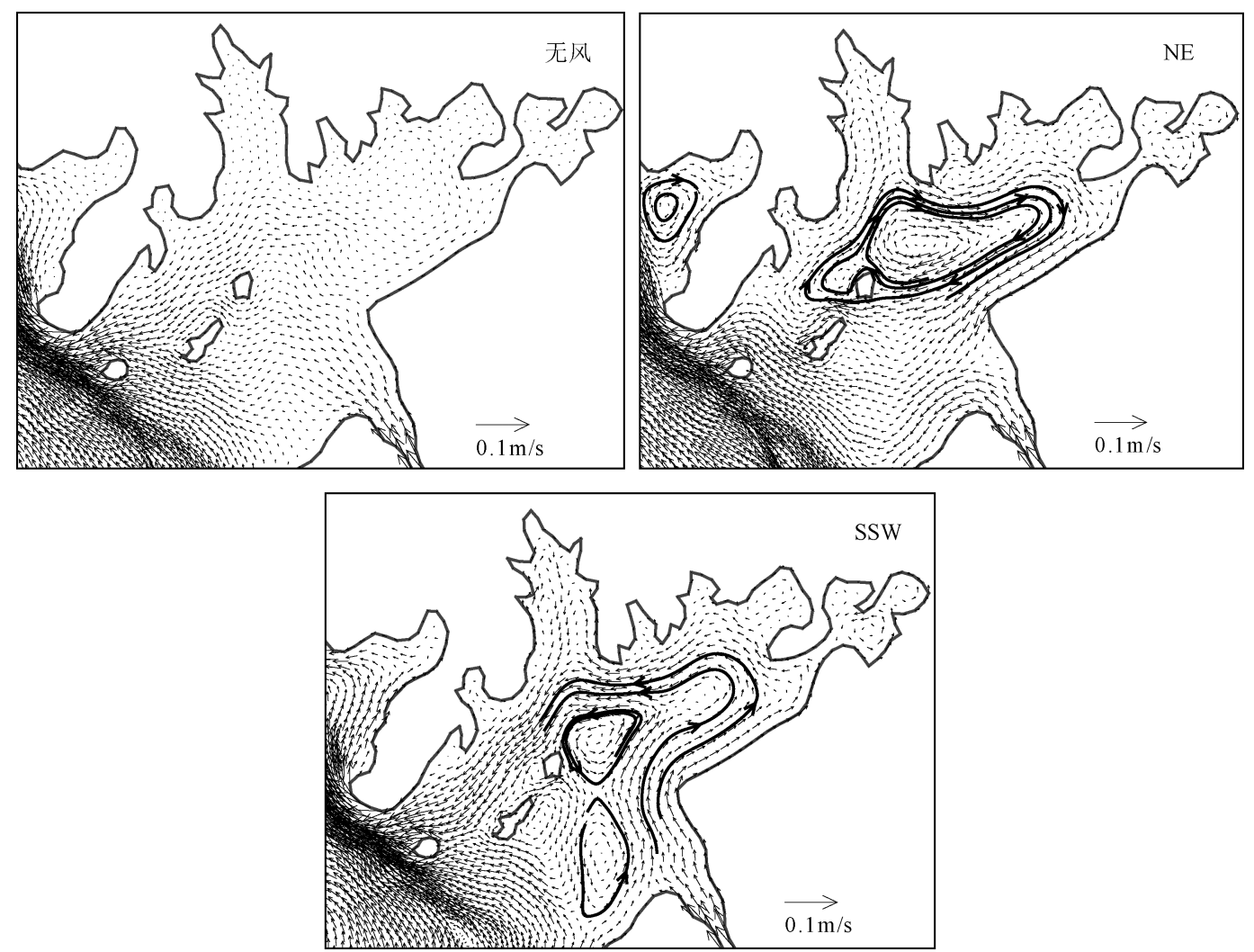

图 9 A 区流场及环流示意图

Fig.9 Flow field and circulation patterns in region A

B 区 (图 10) 在 NE 向风场作用下, 产生顺时针环流; 在 SSW 风场作用下, 产生逆时针环流, 均与 A 区的 主要环流方向一致.

简而言之, 东部湖湾 A、B 区, 在 NE 向风场作用下, 会形成稳定的顺时针环流, 而在 SSW 风场作用下, 相 同区域形成逆时针环流.风生环流的存在使得东部湖湾主河道外的大部分区域流速普遍增大, 但流速量级总 体仍较小.

C 区流场变化最为复杂, 环流并不稳定, 其产生位置和尺度随时空变化显著. 对照水位过程曲线 (图 2) 可知, 7 月底至 8 月底, 水位急剧下降; 8 月底至 9 月底, 水位变化处于相对滞缓期. 因此, 分别选取 8 月 8 日 和 9 月 15 日为两时期典型代表进行流场对比分析( 图 11). 无风状态, 9 月 15 日流速与 8 月 8 日相比整体偏 小, 这与两时段的水位变化相呼应. 在 NE 向风场作用下, 9 月 15 日西北部出现多处尺度不一的环流, 以逆时 针为主, 因该区域处于大湖面, 水深较浅,水下地形复杂, 加之受岛屿掩蔽作用, 极易生成环流; 该区南部, 大 


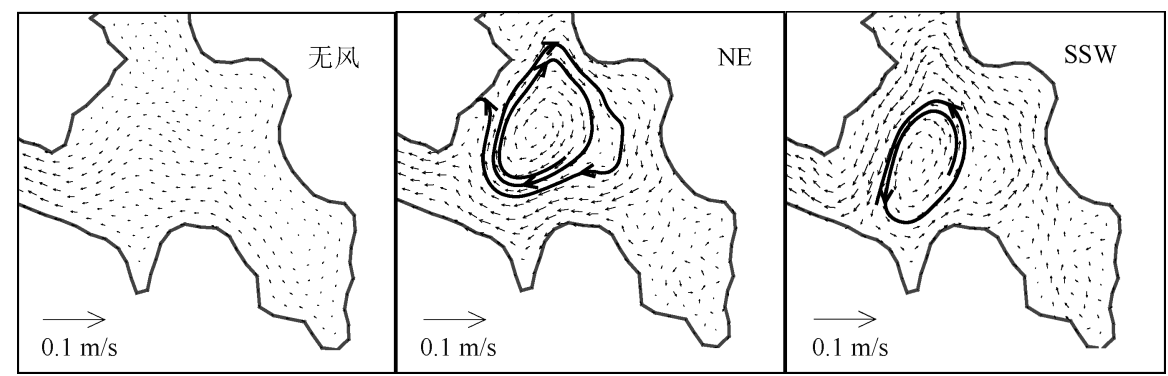

图 $10 \mathrm{~B}$ 区流场及环流示意图

Fig.10 Flow field and circulation patterns in region B

湖面沿岸带,水流明显发生顺时针偏转, 从湖盆地形 (图 1) 可知, 该处地形变化较大, 对风场作用较为敏感; 而 8 月 8 日水位急剧下降, 流速较大, 相对而言受风影响较小, 因而整个西岸都没有形成环流, 只在局部有微 弱的流向变化.SSW 向风场作用下,9 月 15 日,岛屿南侧水流偏转呈 “几” 字形, 并伴有顺时针环流; 西岸在 $\mathrm{NE}$ 向出现明显偏转流的相近位置, 形成逆时针环流;而 8 月 8 日, 虽然也有环流形成, 但整体流态的变化程 度不及前者.
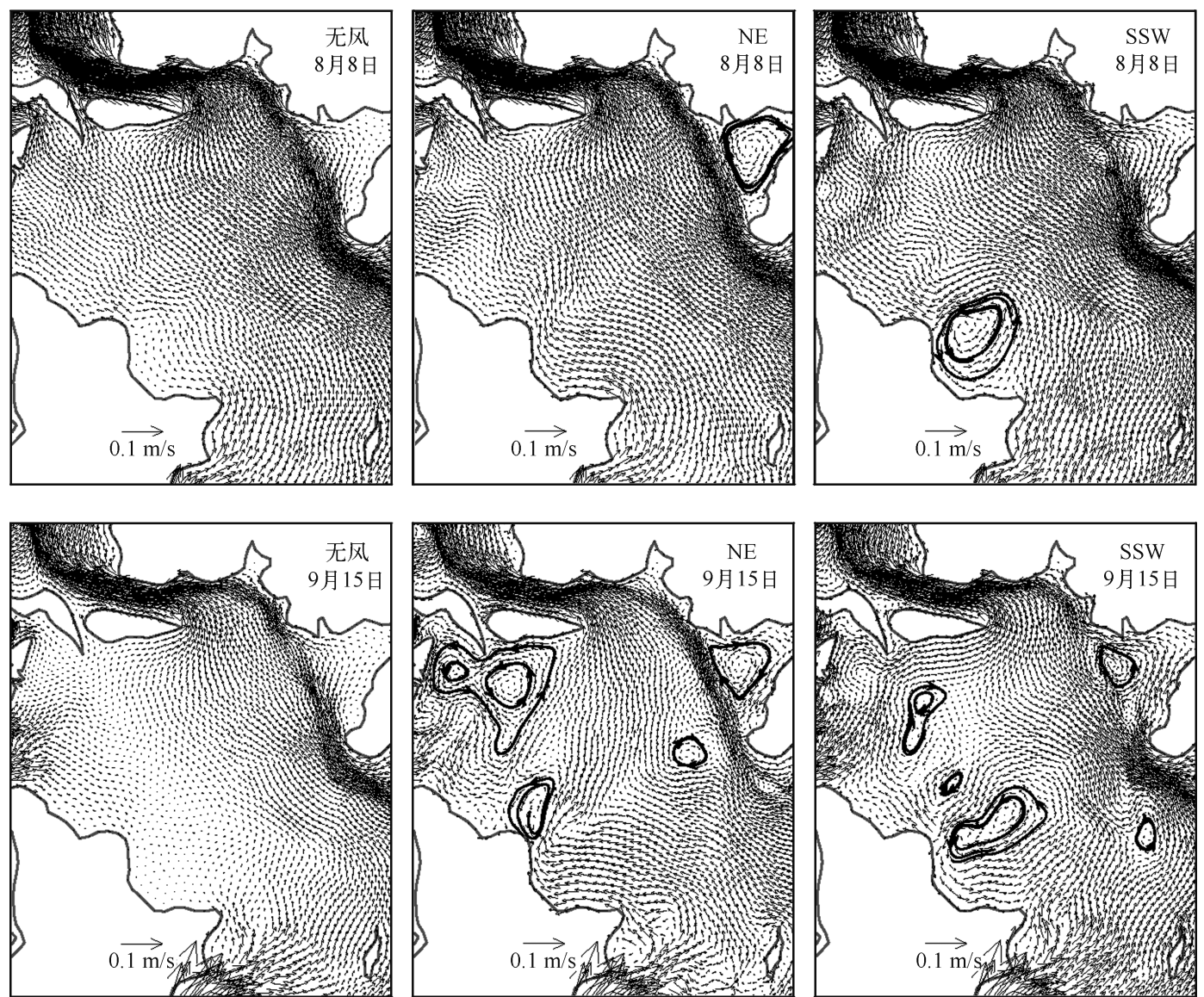

图 $11 \mathrm{C}$ 区流场及环流示意图

Fig.11 Flow field and circulation patterns in region $\mathrm{C}$ 
总体而言, 在 NE 向和 SSW 向风场作用下, C 区在西岸及湖中岛的南侧都易生成环流, 环流位置大致相 同,但方向相反; 水位停滞期整体流速偏小, 受风场影响更明显, 环流尺度更大.

\section{3 讨论}

本文利用有限的风场资料, 采用定常风场, 模拟鄱阳湖风生流的产生时间、位置、环流形态等. 真实的风 场均为非定常风, 本文对于定常风的影响模拟研究, 并不是为了反演某真实风场过程, 而是针对真实风场中 出现频率较高的风向, 研究其影响形式和区域.定常风风场作用下风向和风速固定不变,故环流形式相对稳 定, 持续时间也较长; 而真实风场作用下, 由于风向、风速的频繁变化, 导致环流的大小、方向及结构形式随 之变化, 并非定常风下的一成不变, 环流持续时间也与某风向持续时间相关. 此外需要说明的是, 本文定常风 风速采用的是资料统计的平均值, 对极端风速可能引起的短暂情景未予以考虑.

定常风风速根据 2010 年 1-10 月的风速序列做平均, 缺少 11-12 月大风月资料, 故得到的平均风速 $3.03 \mathrm{~m} / \mathrm{s}$ 比文献[12]里的略小.但本研究主要针对鄱阳湖的两种盛行风, 侧重风向的影响, 风速大小的影响 并非研究重点. 类似的风向对湖泊或海湾水动力影响研究已有不少, 如 Razmi 等 ${ }^{[26]}$ 通过设置多种风向、相同 风速 $(3 \mathrm{~m} / \mathrm{s})$ 的定常风, 测试大型湖泊中开敞式湖湾湖流结构对不同风场的响应, 结果表明: 在大型湖泊中, 即使是很小的湖湾, 也有可能产生复杂流态; 风向发生小角度改变, 湖流结构即发生明显变化. Anderson 等 ${ }^{[27]}$ 通过 8 种主风向和 2 种风速组合的数值模拟发现, 圣克莱尔湖及其三角洲对某些风向较为敏感, 响应 程度也存在较大的空间异质性特点, 某些风场组合条件下, 甚至会出现倒灌流.Guo 等 ${ }^{[2]}$ 模拟了同一风应力 的 4 种定常风 $(\mathrm{NE} 、 \mathrm{NW} 、 \mathrm{SW} 、 \mathrm{SE})$ 对切萨皮克海湾流场和盐度场的时空结构影响, 结果显示, 上、下游海湾对 不同风向的响应并不相同.本研究与上述研究结论相似, 即不同的风向对流场的影响形式不同, 不同区域对 同一风向的响应程度也存在较大差异; 区别在于本文没有对风向影响做广泛测试, 只是集中模拟分析了鄱 阳湖两种盛行风的影响.

以往风生流的研究结果 ${ }^{[28-30]}$ 表明: 相似风向条件下, 风速增大或减小主要影响流速大小, 对环流空间分 布结构不会产生显著影响. 由此认为, 本文的风速模拟结果基本能代表 NE、SSW 风向下的流态结构, 可据此 大致了解风场对鄱阳湖水流的作用方式. 同时, 风生流强弱也受吞吐流量影响 ${ }^{[24]}$, 随着风速量级增大或者吞 吐流量的变化, 是否会在其他区域产生新的环流, 环流形式或形成时间会不会有所差异, 需要在以后的研究 中做进一步的数值模拟测试.

有风、无风条件下的湖泊水流空间结构的差异体现了风场对鄱阳湖的作用, 而无风条件下的水动力场 则反映了“五河” 和长江的作用, 因此本文结果也可阐释“五河”、长江共同作用及风场作用对鄱阳湖水动力 场的贡献差异. 即: 对大部分湖区尤其是主河道而言, 水流主要驱动力为 “五河” 和长江, 只在湖相期, 湖区中 部开阔区部分浅滩和河道, 风场的作用可与 “五河” 和长江作用相当; 对流速极小的局部湖湾如东部湖湾, 风 场贡献甚至可超过 “五河” 和长江. 由于本文只选用一年情景, 并未考虑 “五河” 和长江的多种水情及与不同 风场的组合, 因此对两种驱动力的贡献无法给出详细的对比,这将在下一步工作中继续完善.

风生环流的潜在重要作用使得营养盐在局部区域富集, 影响浮游植物的分布, 有可能导致藻类水华. Ishikawa 等 ${ }^{[31]}$ 通过研究琵琶湖中的蓝藻暴发, 指出环流浴旋对营养物质和藻类运输产生重要作用, 进而对蓝藻 分布产生重要影响.鄱阳湖水质总体较好,但是近年的监测资料对比发现, 鄱阳湖水质呈下降趋势, 某些时段 局部湖区已经发生富营养化,并且整个湖区正缓慢向富营养化趋势发展 ${ }^{[32-34]} . \mathrm{Wu}$ 等 ${ }^{[35]}$ 给出鄱阳湖夏季叶绿 素 a 浓度空间分布 (2009-2012 年), 其中高浓度区主要分布在东部湖湾, 与本研究中的 A、B 区域高度吻 合, 同时指出, 该区域夏季曾观测到蓝藻水华. 这恰好印证了本文环流区分布的合理性, 同时本研究成果也可 从水动力角度对这一现象的解释给予理论支撑.

鄱阳湖湿地生态系统的可持续发展与洲滩湿地的发育和演化密不可分 ${ }^{[36]}$. 在浅水湖泊中, 风成浪对泥 沙再悬浮起着重要作用 ${ }^{[37]}$, 而风生流则影响泥沙的迁移、输运、堆积, 进而影响泥沙冲淤、洲滩发育. 从本研 究结果来看,鄱阳湖局部湖区对风场作用响应明显, 说明风场对局部湖区洲滩发育存在潜在影响.

\section{4 结论}

本文基于鄱阳湖二维水动力数学模型, 通过无风、NE 向和 SSW 向定常风 $(3.03 \mathrm{~m} / \mathrm{s}) 3$ 种情景模拟, 对 
考虑及不考虑风场对鄱阳湖水动力场的影响, 以及两种定常风场的影响差异开展了对比分析. 主要结论为:

1) 该量级风场对湖泊水位影响微弱;对流速影响主要集中在 7 月中旬至 9 月底的“湖相”期,尤其水位 变化越缓,流速越小, 影响越明显.

2) 风场影响区域主要分布在湖区中部大湖面偏西岸及东部湖湾; 上述区域出现明显环流, 环流区面积 可达 $600 \mathrm{~km}^{2}$, 约占湖泊最大水面积的 $16 \%$; 同一风场作用下不同区域环流结构及持续时间也不尽相同, 具 有显著的时空异质性特点; 无论哪种风向作用, 环流区流速平均增至无风状态时两倍以上, 最大增幅 2 $2.5 \mathrm{~cm} / \mathrm{s}$; 其它大部分湖区流速变幅均在 $\pm 0.5 \mathrm{~cm} / \mathrm{s}$ 以内.

3) NE 向和 SSW 向风场产生的环流区位置相近, 环流尺度相似,但方向相反.

4) 涉及“湖相”时期湖区中部西岸及东部湖湾等局部湖区的水动力、物质输移、泥沙冲淤、洲滩发育等 研究时, 风的影响不容忽视.

致谢: 感谢鄱阳湖湖泊湿地观测研究站提供风场资料.

\section{5 参考文献}

[ 1 ] Bloesch J. Mechanisms, measurement and importance of sediment resuspension in lakes. Marine and Freshwater Research, 1995, 46(1) : 295-304.

[ 2 ] Guo XY, Valle-Levinson A. Wind effects on the lateral structure of density-driven circulation in Chesapeake Bay. Continental Shelf Research, 2008, 28: 2450-2471.

[ 3 ] 秦伯强, 胡维平, 陈伟民等. 太湖梅梁湾水动力及相关过程的研究. 湖泊科学, 2000, 12(4): 327-334. DOI 10 . 18307/2000. 0406 .

[ 4 ] 池俏俏, 朱广伟, 张战平等. 风浪扰动对太湖水体悬浮物重金属含量的影响. 湖泊科学, 2006, 18(5): 495-498. DOI 10. 18307/2006. 0509.

[ 5 ] 梁瑞驹, 仲金华. 太湖风生流的三维数值模拟. 湖泊科学, 1994, 6( 4) : 289-297. DOI 10. 18307/1994. 0401.

[6] 逢 勇, 絔培民, 高 光等. 非均匀风场作用下太湖风成流风涌水的数值模拟及验证. 海洋湖沼通报, 1994, (4) : $9-15$.

[ 7 ] 逢 勇, 临培民. 太湖风生流三维数值模拟试验. 地理学报, 1996, 51(4): 322-328.

[ 8 ] 胡维平, 誉培民, 秦伯强. 太湖水动力学三维数值试验研究—-1. 风生流和风涌增减水的三维数值模拟. 湖泊科 学, 1998, 10(4) : 17-25. DOI 10. 18307/1998. 0403.

[ 9 ] 胡维平, 誉培民, 秦伯强. 太湖水动力学三维数值试验研究—-2. 典型风场风生流的数值计算. 湖泊科学, 1998, 10(4) : 26-34. DOI 10. 18307/1998. 0404.

[10] 朱永春, 蔡启铭. 太湖梅梁湾三维水动力学的研究—-I. 模型的建立及结果分析. 海洋与湖沼, 1998, 29(1): $79-85$.

[11] 谭国良, 郭生练, 王 俊等. 鄱阳湖生态经济区水文水资源演变规律研究. 北京: 中国水利水电出版社, 2013.

[12] 熊道光. 鄱阳湖湖流特性分析与研究. 海洋与湖沼, 1991, 22(3) : 200-207.

[13] 汪迎春, 赖锡军, 姜加虎等. 三峡水库调节典型时段对鄱阳湖湿地水情特征的影响. 湖泊科学, 2011, 23(2): 191-195. DOI 10. 18307/2011. 0205.

[14] 赖锡军, 姜家虎, 黄 群等. 鄱阳湖二维水动力和水质耦合数值模拟. 湖泊科学, 2011, 23 (6) : 893-902. DOI 10. 18307/2011. 0611.

[15] 李云良, 张 奇, 姚 静等. 鄱阳湖湖泊流域系统水文水动力联合模拟. 湖泊科学, 2013, 25(2): 227-235. DOI 10. $18307 / 2013.0208$.

[16] Li YL, Zhang Q, Yao J et al. Hydrodynamic and hydrological modeling of the Poyang Lake catchment system in China. Journal of Hydrologic Engineering, 2014, 19(3) : 607-616.

[17] 王 鹏, 赖格英, 黄小兰. 鄱阳湖水利枢纽工程对湖泊水位变化影响的模拟. 湖泊科学, 2014, 26 (1) : 29-36. DOI 10. 18307/2014. 0104.

[18］尹宗贤，张俊才. 鄱阳湖水文特征( II ). 海洋与湖沼, 1987，18(2) : 208-214.

[19] 程时长, 卢 兵. 鄱阳湖湖流特征. 江西水利科技, 2003, 29(2) : 105-108.

[20] Wu J. The sea surface is aerodynamically rough even under light winds. Boundary Layer Meteorology, 1994, 69: 149-158.

[21] Wu J. Wind-stress coefficients over sea surface and near neutral conditions-a revisit. Journal of Physical Oceanography, 
1980, 10: 727-740.

[22]谭国良, 李国文, 喻中文等. 鄱阳湖动态水位一面积一容积关系研究. 中国水利学会 2013 学术年会论文集一S2 湖 泊治理开发与保护. 北京: 中国水利水电出版社, 2013: 736-742.

[23] 程时长, 李良文. 鄱阳湖的风情及风浪特性. 海洋湖沼通报, 1993，4: 1-12.

[24] 韩红娟, 胡维平, 晋义泉. 风速变化对竹湖流场结构影响的数值试验. 海洋与湖沼, 2008, 39(6) : 567-576.

[25] Schoen JH, Stretch DD, Tirok K. Wind-driven circulation patterns in a shallow estuarine lake: St Lucia, Estuarine, South Africa. Coastal and Shelf Science, 2014, 146: 49-59.

[26] Razmi AM, Barry DA, Bakhtyar R et al. Current variability in a wide and open lacustrine embayment in Lake Geneva (Switzerland). Journal of Great Lakes Research, 2013, 39: 455-465.

[27] Anderson EJ, Schwab DJ. Relationships between wind-driven and hydraulic flow in Lake St. Clair and the St. Clair River Delta. Journal of Great Lakes Research, 2011, 37: 147-158.

[28］姜加虎. 贡湖及其相关水域风生流模拟研究. 海洋湖沼通报, 1997, (4): 1-7.

[29] 曹慧江, 杨 芸, 朱建荣. 滴水湖夏季环流的三维数值模拟. 华东师范大学学报: 自然科学版, 2006, 4: 78$83,90$.

[30］韩龙喜, 陆东燕, 李洪晶等. 高盐度湖泊艾比湖风生流三维数值模拟. 水科学进展, 2011, 22(1) : 97-103.

[31] Ishikawa K, Kumagai M, Vincent WF et al. Transport and accumulation of bloom-forming cyanobacteria in a large, midlatitude lake: the gyre Microcystis hypothesis. Limnology, 2002, 3(2): 87-96.

[32] 吕兰军. 鄱阳湖富营养化调查与评价. 湖泊科学, 1996, 8(3): 241-247. DOI 10. 18307/1996. 0308.

[33] 王毛兰, 周文斌, 胡春华. 鄱阳湖区水体氮、磷污染状况分析. 湖泊科学, 2008, 20(3) : 334-338. DOI 10. 18307/ 2008. 0311 .

[34] 胡春华, 周文斌, 王毛兰等. 鄱阳湖氮磷营养盐变化特征及潜在性富营养化评价. 湖泊科学, 2010, 22(5)：723728. DOI 10. 18307/2010. 0514.

[35] Wu ZS, He H, Cai YJ et al. Spatial distribution of chlorophyll a and its relationship with the environment during summer in Lake Poyang: a Yangtze-connected lake. Hydrobiologia, 2014, 732: 61-70.

[36] 葛 刚, 纪伟涛, 刘成林等. 鄱阳湖水利枢纽工程与湿地生态保护. 长江流域资源与环境, 2010, 19(6): 606-613.

[37] Qian J, Zheng SS, Wang PF et al. Experimental study on sediment resuspension in Taihu Lake under different hydrodynamic disturbances. Journal of Hydrodynamics, 2011, 23(6) : 826-833. 